\title{
Epigenetics Lights Up the Obesity Field
}

\author{
Amelia Marti ${ }^{a, b} \quad$ Jose Ordovas ${ }^{b, c, d}$ \\ ${ }^{a}$ Department of Food Science and Nutrition, Physiology and Toxicology, Pharmacy School, University of Navarra, Pamplona, Navarra, Spain \\ ${ }^{\mathrm{b}}$ Nutrition and Genomics Laboratory, Jean Mayer USDA Human Nutrition Research Center on Aging, Tufts University, Boston, MA, USA \\ c IMDEA Alimentacion, \\ ${ }^{d}$ Department of Epidemiology, Atherothrombosis and Imaging, CNIC, Madrid, Spain
}

Blundell et al. [1] in a recent OBESITy FAcTs' editorial challenges the reader with an interesting open question: 'What is the part of epigenetics and other 'omics' in obesity research?' The current editorial takes up the gauntlet thrown down by these authors and attempts to define the state of the art of this topic. 'Omics' tools have become essential to gain a more integrated and functional knowledge of the workings of cells as well as entire organisms, and the current evidence suggests that these advances will provide new opportunities for prevention, diagnosis, treatment and monitoring of obesity.

So far, most of the 'omics' efforts in the obesity arena have been devoted to characterize the mechanisms of obesity onset [2-6]. This process started back in the 1990s with the development of experimental models of obesity and the microarray technologies and continues today with the addition of more advanced 'omics' technologies, but above all with more experienced researchers in the use and interpretation of these technologies. The human component of the 'omics' revolution started in 2006 thanks to the widespread availability of genome arrays and the subsequent proliferation of genome wide association studies [7-9]. These efforts have resulted in the identification of about 40 loci related to human obesity. Of those, FTO has been the most replicated and the one showing the highest statistical significance. However, despite these advances, the combined effect of all loci identified so far account for about $2-3 \%$ of the inherited contribution to obesity risk (40-70\%).

These humbling statistics confirm the complex nature of obesity and the need to identify additional factors including interactions between multiple genes and environmental factors [10-12]. Moreover, epigenetic modifications may be responsible for a significant proportion of the apparent missing heritability as well as the mechanisms by which the environment could induce metabolic changes with lasting effects.

\section{The Birth of Epigenetics}

In the early 1940s, Conrad Waddington coined the term 'epigenetics' (from the Greek: 'beyond genetics') to explain the causal interactions between genes and their products, which bring the phenotype into being [13-15]. But the first mechanistic evidence supporting the concept was provided by Holliday and Pugh [14] through their work on DNA methylation and gene activity during development. The next breakthrough came with the identification of histone modification in the mid-1990s and the realization that the DNA world was truly three-dimensional, given the role of chromatin structure in the regulation of gene expression [14]. Therefore, methylation and histone modifications were the original epigenetic markers. More recently, the discovery of noncoding RNAs, including microRNAs (miRNAs), provided further evidence for epigenetic effects through post-translational mechanisms. miRNAs are small RNAs, approximately 22 nucleotides in length, that repress the expression of mRNAs after binding to small sequences of total or partial complementarity [14].

Overall, epigenetics refers specifically to the study of mitotically and/or meiotically hereditable changes in gene expression that occur without changes in the DNA sequence [13]. The difference between genetics and epigenetics can probably be compared to the difference between having all the letters of a text (the DNA sequence) and knowing how to combine them into meaningful words (epigenetic modifications).

In recent years epigenetic research is a booming field as illustrated in table 1 . The fruits of this research are being harvested already in the cancer field with the release of the first therapeutic agents based on epigenetic mechanisms [13]. But this trip has not been either easy or short, considering that the first publications in cancer epigenetics date back to the 1970s.

\section{KARGER \\ Fax +497614520714 \\ Information@Karger.de}

www.karger.com (c) 2011 S. Karger GmbH, Freiburg

$1662-4025 / 11 / 0043-0187 \$ 38.00 / 0$

Accessible online at:

www.karger.com/ofa
Prof. Dr. Amelia Marti

Department of Food Science, Nutrition, Physiology and Toxicology

Pharmacy School, University of Navarra

Irunlarrea 1, 31001 Pamplona, Navarra, Spain

amarti@unav.es 
Table 1. Summary of projects, programs and resources on epigenomic research ${ }^{\mathrm{a}}$

\begin{tabular}{|c|c|c|}
\hline Name & Aim & Website \\
\hline The Human Epigenome Atlas & $\begin{array}{l}\text { The Human Epigenome Atlas includes human reference } \\
\text { epigenomes and the results of their integrative and } \\
\text { comparative analyses. It is produced by the NIH } \\
\text { Epigenomics Roadmap Consortium }\end{array}$ & www.genboree.org/epigenomeatlas/index.rhtml \\
\hline NCBI Epigenomics Gateway & $\begin{array}{l}\text { Curated, annotated and organized epigenetics-specific } \\
\text { data selected from general-purpose archives, such as the } \\
\text { Gene Expression Omnibus, and Sequence Read Archives }\end{array}$ & www.ncbi.nlm.nih.gov/epigenomics \\
\hline $\begin{array}{l}\text { Human Epigenome Project } \\
\text { (HEP) }\end{array}$ & $\begin{array}{l}\text { The HEP aims to identify, catalogue and interpret } \\
\text { genome-wide DNA methylation patterns of all human } \\
\text { genes in all major tissues }\end{array}$ & www.epigenome.org \\
\hline RoadmapEpigenomics Project & $\begin{array}{l}\text { The NIH Roadmap Epigenomics Mapping Consortium } \\
\text { was launched with the goal of producing a public resource } \\
\text { of human epigenomic data to catalyze basic biology and } \\
\text { disease-oriented research }\end{array}$ & $\begin{array}{l}\text { www.roadmapepigenomics.org/ } \\
\text { www.epigenomebrowser.org/ } \\
\text { http://genomebrowser.wustl.edu/ }\end{array}$ \\
\hline $\begin{array}{l}\text { Epigenesys Network of } \\
\text { Excellence (Epigenesys) }\end{array}$ & $\begin{array}{l}\text { A new ambitious EC-funded research initiative on } \\
\text { Epigenetics advancing towards systems biology }\end{array}$ & www.epigenesys.eu/ \\
\hline $\begin{array}{l}\text { National Methylome } 21 \\
\quad \text { (NAME21) }\end{array}$ & $\begin{array}{l}\text { NAME21 aims to generate a first comprehensive DNA } \\
\text { methylation map on human chromosome } 21 \text { using } \\
\text { bisulphite sequencing technologies }\end{array}$ & http://biochem.jacobs-university.de/name21/ \\
\hline $\begin{array}{l}\text { Epigenetic Treatment of } \\
\text { Neoplastic Disease } \\
\text { (EPITRON) }\end{array}$ & EPIgenetic TReatment Of Neoplastic disease & www.epitron.eu \\
\hline $\begin{array}{l}\text { Highthroughput Epigenetic } \\
\text { Regulatory Organization } \\
\text { In Chromatin (HEROIC) }\end{array}$ & $\begin{array}{l}\text { The HEROIC Project High-throughput Epigenetic } \\
\text { Regulatory Organisation In Chromatin }\end{array}$ & www.heroic-ip.eu \\
\hline $\begin{array}{l}\text { AACR Human Epigenome } \\
\text { Taskforce and Alliance for } \\
\text { the Human Epigenome and } \\
\text { Disease (AHEAD) }\end{array}$ & $\begin{array}{l}\text { America Association Cancer Research (AACR) Human } \\
\text { Epigenome Taskforce to implement the Alliance for the } \\
\text { Human Epigenome and Disease (AHEAD) Project }\end{array}$ & $\begin{array}{l}\text { www.aacr.org/home/scientists/working-groups-task- } \\
\text { forces/task-forces/human-epigenome-task-force.aspx }\end{array}$ \\
\hline $\begin{array}{l}\text { The Common Fund's } \\
\text { Epigenomics Program at NIH }\end{array}$ & $\begin{array}{l}\text { The Epigenomics Program is part of the International } \\
\text { Human Epigenome Consortium that aims to coordinate } \\
\text { worldwide epigenome mapping and characterization } \\
\text { efforts }\end{array}$ & http://commonfund.nih.gov/epigenomics/ \\
\hline $\begin{array}{l}\text { International Human Epigenome } \\
\text { Consortium (IHEC) }\end{array}$ & $\begin{array}{l}\text { IHEC will coordinate epigenome mapping and } \\
\text { characterisation worldwide to avoid redundant research } \\
\text { effort, to implement high data quality standards, } \\
\text { to coordinate data storage, management and analysis } \\
\text { and to provide free access to the epigenomes produced }\end{array}$ & http://ihec-epigenomes.org/index.html \\
\hline
\end{tabular}

The head start of cancer in epigenetics is easily quantified by doing a PubMed search using the terms 'epigenetic' plus 'cancer.' This provides about 8,491 hits (www.ncbi.nlm.nih. gov/pubmed?term = epigenetic\%20cancer, May 31, 2011). These numbers contrast with the paucity of results obtained for a similar search using the terms 'epigenetic' plus 'obesity' with only 275 hits (www.ncbi.nlm.nih.gov/pubmed?term $=$ epigenetic\%20obesity, May 31, 2011). In fact, the initial connection between epigenetics and obesity took place indirectly through a relatively rare inherited disease: the Prader-Willi Syndrome (PWS), a congenital condition characterized by severe obesity [16]. In the clinical diagnosis of PWS, there are three distinct mechanisms that lead to lack of expression of paternally inherited genes in the 15q11.2-q13 region: paternal microdeletion $(70 \%)$, maternal uniparental disomy $(25-30 \%)$ and an imprinting defect $(1 \%)$. Regardless of the specific causes, over $99 \%$ of PWS cases can be diagnosed using DNA methylation analysis. 


\section{Epigenetic Marks and Common Obesity}

Work on the three main epigenetic marks and mechanisms involving adipose tissue and obesity has just started. Some relevant progress is presented here:

i) Genomic DNA methylation. This is a major epigenetic modification that controls gene expression in physiologic and pathologic states [17]. Methylation results from the addition of a methyl group to a cytosine positioned next to a guanine nucleotide (CpGs) usually in regions with a high presence of $\mathrm{CpG}$ di nucleotides (>60\%).

Methylation in a promoter region results in the repression (silencing) of gene expression through a number of mechanisms including: obstruction of access to transcription factors/activators and recruitment of co-repressors (like histone deacetylases), which alter chromatin structure resulting in failure to initiate transcription $[9,17]$. Less frequently, methylation can also lead to gene activation when it occurs at somatic genes [18].

It appears that DNA methylation plays a role in the regulation of key genes involved in the regulation of glucose homeostasis. The promoter of the insulin (INS) gene is demethylated in insulin-producing cells. The methylation of Ins2 promoter also leads to the binding of methyl $\mathrm{CpG}$ binding protein 2, which further suggests a mechanism for silencing the INS gene [19]. Glucose transporter 4 (GLUT 4) which translocates to the plasma membrane in response to insulin in adipose tissue and skeletal muscle, is a critical player in glucose homeostasis [17]. The GLUT4 promoter is highly demethylated upon adipocyte differentiation, and methylation at specific $\mathrm{CpG}$ sites can inhibit nuclear factor binding to the promoter. Similarly, the peroxisome proliferator-activated receptor gamma 2 (PPARG2) gene is progressively demethylated upon adipocyte differentiation, which provides evidence that DNA methylation sets the adipocyte-specific gene expression [20].

The methylation status is altered in the adipose tissue of inborn and diet-induced obese mice such that hypermethylation of the $-437 \mathrm{CpG}$ site upstream of the transcription start site of the PPARG2 gene was observed in omental adipose tissue of obese animals. Also rats raised in small litters become obese because of overfeeding, develop hyperglycemia and hyperinsulinemia, along with hypermethylation of the proopiomelanocortin (POMC) gene [17]. Similarly, shortterm overfeeding altered peroxisome proliferator-activated receptor gamma coactivator 1 alpha (PGC1alpha) promoter methylation in matched normal-weight individuals.

Potential interactions between the environment and epigenetic modifications mediating the expression of genes associated with adiposity may also be possible for: a) the FTO gene which is a DNA-demethylase enzyme, b) the melanocortin 4 receptor $(M C 4 R)$ gene with a decrease in methylation after long-term exposure to a high fat diet, c) the PPARG protein which interacts with histone acetyl- transferases during adipogenesis and on the effect of diet on methylation of POMC and leptin [9].

ii) Changes in chromatin organization by histone modifications. It is worthy to keep in mind that DNA in cells is packaged as chromatin in a 'beads on a string' configuration. The fundamental unit of chromatin is the nucleosome, which consists of $146 \mathrm{bp}$ of DNA wrapped around a histone octamer (made up of two copies of four core histones: H2A, H2B, H3, H4). The N-terminal histone is subjected to a variety of post-translational modifications that include acetylation, methylation, phosphorylation and ubiquination [21]. Gene activation correlates with the hyperacetylation of histones $\mathrm{H} 3$ and $\mathrm{H} 4$, whereas hypoacetylation correlates with inactive chromatin.

In adipocyte differentiation it has been shown that PPARG targets are many genes encoding chromatin modification enzymes as well as genes involved in lipid metabolism and storage [21]. Histone methylation is catalyzed by histone methyltranferases and reversed by histone demethylase. Two groups have reported recently the role of histone demethylase JHDM2a (lysine (K)-specific demethylase 3A, which catalyzes the removal of $\mathrm{H} 3 \mathrm{~K} 9$ mono or dimethylation through iron) in the protection from obesity since mice deficient in JHDM2a develop adult onset obesity [22-23]. Tateishi et al. [22] proposed that the obese phenotype is due to the loss of JHDM2a which is crucial in regulating metabolic control through PPAR- $\alpha$ and beta-adrenergic signaling pathways.

iii) Noncoding RNAs or miRNAs. They normally bind to the 3-UTR (untranslated region) of their target mRNA through imperfect base pairing, leading to translation inhibition and/or mRNA degradation. Over 500 miRNAs have been found in the human genome, and it has been estimated that they could regulate $74-92 \%$ of all proteinencoding mRNAs [24]. Considering the complex level of gene expression regulation conferred by miRNAs, it comes as no surprise that miRNAs are involved in processes associated with obesity, such as adipocyte differentiation, insulin action and fat metabolism [24-26].

Recent studies show that miRNAs are dysregulated in obese adipose tissue. During adipogenesis miRNAs can accelerate or inhibit adipocyte differentiation and hence regulate fat cell development. In addition, miRNAs may regulate adipogenic lineage commitment in multipotent stem cells and govern fat cell numbers.

The first miRNA found to play a role in maturation of human adipocytes was miR-143 [24-26]. miR-143 and also miR-103 can induce adipogenesis in 3T3-L1 adipocytes and augment or accelerate expression of several key adipogenesis-regulated genes such as fatty-acid binding protein $(F A B P)$ and adiponectin gene [24]. Activation of the miRNA cluster miR-17 92 enhances adipogenesis while let-7 and miR-27 impair adipogenic differentiation [24]. Several miRNAs are upregulated in adipose tissue in animal models of 
metabolic disease and/or obesity, e.g., mir-125a, mir29 and mir-143, while adipose tissue miR-519d expression is associated with human obesity [25]. In adipocytes, both miR-27 and miR-519d target PPAR family members, which are well established regulators of fat cell development.

The potential of miRNA-based therapeutics targeting obesity is high and might lead to breakthroughs in the treatment of obesity.

Interestingly, epigenetic processes work together to establish and maintain the globally and locally condensed or uncondensed chromatin states that eventually drives gene expression. The continuous interplay of these processes creates the 'epigenome,' the epigenetic status that determines the way a single eukaryotic genome may manifest itself in different cell types and developmental stages and under specific environmental situations. This orchestration, if aberrant, leads to impaired homeostasis and disease development.

\section{Perspectives on Epigenetics and Obesity}

2011 marks the 10th anniversary of the publications that reported the initial human genome sequence. It was stated that the complete genome sequence would 'revolutionize the diagnosis, prevention, and treatment of most, if not all, human diseases.' Whereas this is probably true, the question remains about 'when' and 'how'.

During this past decade genetic discoveries have provided a molecular basis for clinically useful classification of monogenic forms of obesity but the data are insufficient to support management decisions for common forms of obesity.
At this moment, it is crucial to gather evidence from a wide range of sources - including genetic predisposition (genome), epigenetic changes (epigenome), gene expression (transcriptome), protein synthesis and modification (proteome) as well as metabolite distribution (metabolome) - to facilitate the understanding of the biological mechanisms that underlie common obesity pathophysiology in humans.

Regarding one of the most novel and exciting 'omics' in the field of obesity research, an epigenetic framework [26] could help to better understand the etiology of obesity, specifically:

- the age-dependency (late onset and progressive nature of most common diseases),

- the quantitative nature (complex traits),

- the mechanism by which the environment might modulate genetic predisposition to obesity.

Furthermore, the application of new genome scale tools for epigenetic analysis will allow us to determine the relationship between genetic variation, epigenetic variation and disease simultaneously. Interestingly, the door for the integration of the epigenomic and other 'omics' information on obesity is just opening.

\section{Acknowledgements}

Dr. Marti was awarded a fellowship from FUNDACION MAPFRE. This work was supported by Navarra Government (Health Department: project 54/2009), National Heart, Lung, and Blood Institute grants HL-54776, and U01 HL72524; National Institute of Diabetes and Digestive and Kidney Diseases, Grant Number DK075030 and by contracts 53-K06-5-10 and 58-1950-9-001 from the US Department of Agriculture Research.

\section{References}

1 Blundell JE, Hebebrand J, Oppert JM: What is the value of obesity research? Obes Facts 2010;3: 279-282.

2 Marti A, De Miguel C, Jebb SA, et al: Methodological approaches to assess body-weight regulation and aetiology of obesity. Proc Nutr Soc 2000; 59:405-411.

3 Moreno-Aliaga MJ, Marti A, García-Foncillas J, et al: DNA hybridization arrays: a powerful technology for nutritional and obesity research. Br J Nutr 2001;86:119-122.

4 Speakman J, Hambly C, Mitchell S, et al: The contribution of animal models to the study of obesity. Lab Anim 2008;42:413-432.

$\checkmark 5$ Kennedy AJ, Ellacott KL, King VL, et al: Mouse models of the metabolic syndrome. Dis Model Mech 2010;3:156-166.

6 Kim Y, Park T: DNA microarrays to define and search for genes associated with obesity. Biotechnol J 2010;5:99-112.

7 Hinney A, Hebebrand J: Polygenic obesity in humans. Obes Facts 2008;1:35-42.

$\checkmark 8$ McCarthy MI: Genomics, type 2 diabetes, and obesity. N Engl J Med 2010;363:2339-2350.

9 Herrera BM, Keildson S, Lindgren CM: Genetics and epigenetics of obesity. Maturitas 2011;69:41-49.

10 Marti A, Martinez-Gonzalez MA, Martinez JA Interaction between genes and lifestyle factors on obesity. Proc Nutr Soc 2008;67:1-8.
11 Ordovás JM, Robertson R, Cléirigh EN: Genegene and gene-environment interactions defining lipid-related traits. Curr Opin Lipidol 2011;22: 129-136.

12 Razquin C, Marti A, Martinez JA: Evidences on three relevant obesogenes: MC4R, FTO and PPAR $\gamma$. Approaches for personalized nutrition. Mol Nutr Food Res 2011;55:136-149.

13 Rodríguez-Paredes M, Esteller M: Cancer epigenetics reaches mainstream oncology. Nat Med 2011;17:330-339.

14 Ordovás JM, Smith CE: Epigenetics and cardiovascular disease. Nat Rev Cardiol 2010;7:510-519.

15 Campión J, Milagro FI, Martínez JA: Individuality and epigenetics in obesity. Obes Rev 2009;10:383392.

16 Jin DK: Systematic review of the clinical and genetic aspects of Prader-Willi syndrome. Korean J Pediatr2011;54:55-63.

17 Barres R, Zierath JR: DNA methylation in metabolic disorders. Am J Clin Nutr 2011;93:897S-900S.

18 Portela A, Esteller M: Epigenetic modifications and human disease. Nat Biotechnol 2010;28:10571068.

19 Kuroda A, Rauch TA, Todorov I, et al: Insulin gene expression is regulated by DNA methylation. PLoS One 2009;4:e6953..
20 Fujiki K, Kano F, Shiota K, et al: Expression of the peroxisome proliferator activated receptor gamma gene is repressed by DNA methylation in visceral adipose tissue of mouse models of diabetes. BMC Biol 2009;7:38.

21 Okamura M, Inagaki T, Tanaka T, et al: Role of histone methylation and demethylation in adipogenesis and obesity. Organogenesis 2010;6:24-32.

22 Tateishi K, Okada Y, Kallin EM, et al: Role of Jh$\mathrm{dm} 2 \mathrm{a}$ in regulating metabolic gene expression and obesity resistance. Nature 2009;458:757-761.

23 Inagaki T, Tachibana M, Magoori K, et al: Obesity and metabolic syndrome in histone demethylase JHDM2a-deficient mice. Genes Cells 2009;14:9911001.

24 Hulsmans M, De Keyzer D, Holvoet P: MicroRNAs regulating oxidative stress and inflammation in relation to obesity and atherosclerosis. FASEB J 2011; doi: 10.1096/fj.11-181149.

25 Ortega FJ, Moreno-Navarrete JM, Pardo G, et al: MiRNA expression profile of human subcutaneous adipose and during adipocyte differentiation. PLoS One 2010;5:e9022.

26 Feinberg AP: Epigenomics reveals a functional genome anatomy and a new approach to common disease. Nat Biotechnol 2011;28:1049-1052.

27 Beck S, Rakyan VK: The methylome: approaches for global DNA methylation profiling. Trends Genet 2008;24:231-237. 